\title{
COMPARISON OF INBRED LINES PRODUCED BY SINGLE SEED DESCENT AND PEDIGREE INBREEDING
}

\author{
J. L. JINKS AND H. S. POONI \\ Department of Genetics, University of Birmingham, P.O. Box 363, Birmingham B15 2 TT \\ Received 13.ii.84
}

\begin{abstract}
SUMMARY
Large random samples of inbred families extracted from the highly heterotic cross of varieties 2 and 12 of Nicotiana rustica by single seed descent ( 60 families) and pedigree inbreeding ( 784 families) have been compared for seven quantitative characters. As expected on theoretical grounds there were no differences in the phenotypic and genotypic properties of the inbred families ascribable to the method used for their extraction. The samples confirmed that inbred families which outperform the heterotic $F_{1}$ can be readily extracted from it by either method.

The hierarchical structure of the pedigree inbred families allowed a more sophisticated genetical analysis than the simple structure of the single seed descent families. But while the more complex structure allowed the detection of repulsion linkage for five of the seven characters, non-allelic interaction was detected for only one of them. The pedigree inbred families do not, therefore, provide a sensitive test for the non-allelic interactions which are detected by analyses of alternative designs.
\end{abstract}

\section{INTRODUCTION}

In all circumstances except where differential selection has been deliberately or unconsciously imposed, the properties of the recombinant inbred lines extractable from a cross by pedigree inbreeding (PI) and single seed descent (SSD) should be identical (Jinks and Pooni, 1981b) and these properties should be predictable from estimates of genetical components obtained from the early generations of the cross (Jinks and Pooni, 1976, 1980; Pooni and Jinks, 1978, 1979; Pooni, Jinks and Jayasekara, 1978; Pooni, Jinks and Pooni, 1978). Over a wide range of circumstances estimates of genetical components from a combination of an $\mathrm{F}_{2}$ triple test cross (Kearsey and Jinks, 1968) and the basic generations (Jinks and Pooni, 1976) have provided reliable predictions (Pooni and Jinks, 1978; Jinks and Pooni, 1980). Satisfactory predictions have also been obtained from other early generation analyses, including small random samples of the $F_{3}$ families of the cross (Jinks and Pooni, 1980; Pooni and Jinks, 1981 $a$ ). In this paper we shall, for the first time, compare the properties of random samples of the recombinant inbred lines extracted from a cross by pedigree inbreeding and single seed descent and their relative values as sources of genetical information.

\section{Materials AND MEthod}

The cross of varieties 2 and 12 of $N$. rustica has been widely investigated because it is highly heterotic (see Pooni, Jinks and Jayasekara, 1978 and Jinks, 1983, for summaries). Sixty single seed descent inbreds were produced from a random sample of $60 \mathrm{~F}_{2}$ plants of this cross. To make the pedigree 
inbred families comparable with the SSD inbreds they were produced without deliberate selection. To achieve this, 98 randomly chosen $F_{2}$ plants were self-pollinated to produce $98 \mathrm{~F}_{3}$ families, two randomly chosen plants from each $F_{3}$ family were self-pollinated to produce $196 F_{4}$ families, two randomly chosen plants from each $\mathrm{F}_{4}$ family were self-pollinated to produce $392 F_{5}$ families and two randomly chosen plants from each $F_{5}$ family were self-pollinated to produce $784 \mathrm{~F}_{6}$ families. The $\mathrm{F}_{2}, \mathrm{~F}_{3}, \mathrm{~F}_{4}, \mathrm{~F}_{5}$ and $\mathrm{F}_{6}$ were raised in replicated, randomised field trials and the seven characters described later recorded on them. These trials were not, however, used at this stage to practice selection on the pedigree inbreds (see section 4).

The seed for the field comparison of the SSD and PI families was produced by self-pollinating one plant from each of the 60 inbred families $\left(F_{12}\right)$ produced by single seed descent and from each of the 784 families $\left(F_{6}\right)$ produced by pedigree inbreeding. The seed sown was, therefore, $F_{13}$ and $F_{7}$, respectively. The original parental varieties, 2 and 12 , their reciprocal $F_{1}$ and $F_{2}$ families and random samples of $10 F_{3}$ and 10 reciprocal $F_{3}$ families were included as controls, making a total of 870 families.

Because of the large number of families, the experiment was divided into two blocks. Each block contained all 60 single seed descent inbred families and the parents, reciprocal $F_{1}$ 's and $F_{2}$ 's but only half of the $20 F_{3}$ and 784 pedigree inbred families. The latter were divided such that all the $392(49 \times 8) \mathrm{F}_{7}$ families derived from 49 of the original $98 \mathrm{~F}_{2}$ plants were raised in each block. Eight replicate plants of each of the 452 inbred families and 10 replicate plants of each of the 16 control families were raised in each block. The whole experiment, therefore, consisted of 7552 plants (3776 per block) with all plants individually randomised within a block.

The following characters were recorded on individual plants:-

H4 Plant height $(\mathrm{cm}) 4$ weeks after planting in field

H6 Plant height $(\mathrm{cm}) 6$ weeks after planting in field

FT Flowering time (days)

HFT Plant height $(\mathrm{cm})$ at time of flowering

LL Length of largest leaf $(\mathrm{cm})$

LW Width of largest leaf $(\mathrm{cm})$

FH Final plant height $(\mathrm{cm})$

Because of damage during the growing season no data were collected on 165 plants and only three or four characters could be scored on 16 others (see tables 2, 3 and 5).

\section{Results}

\section{(i) Comparison of SSD and PI families}

The means and standard errors of the random samples of inbred lines produced by single seed descent and pedigree inbreeding are given for each character in table 1 . It is quite clear that the procedure used to extract the inbred lines from the cross of varieties 2 and 12 has had no significant effect on the means of the samples obtained for any of the seven characters. Indeed the agreement between the two sets of means is remarkably good.

Analyses of variance of the 60 inbred lines produced by SSD and of the 784 produced by PI for the seven characters are summarised in tables 2 and 3, respectively. For the SSD lines we have 60 families each represented by 8 replicate plants in each of the two replicate blocks, making 960 plants 
TABLE 1

The overall means of the random samples of inbred families produced by single seed descent $(S S D)$ and pedigree inbreeding $(P I)$, respectively

\begin{tabular}{ccr} 
& \multicolumn{2}{c}{ Source of inbred families } \\
\cline { 2 - 3 } Character & \multicolumn{1}{c}{ SSD } & \multicolumn{1}{c}{ PI } \\
\hline H $_{4}$ & $11.94 \pm 0.76^{*}$ & $12.14 \pm 0.50$ \\
H $_{6}$ & $44.42 \pm 1.80$ & $44.78 \pm 1.08$ \\
FT & $25.67 \pm 1.16$ & $25.00 \pm 0.73$ \\
HFT & $67.45 \pm 2.85$ & $65.61 \pm 1.49$ \\
LL & $21.73 \pm 0.46$ & $21.53 \pm 0.25$ \\
LW & $17.25 \pm 0.48$ & $17.03 \pm 0.28$ \\
FH & $124.07 \pm 3.26$ & $125.86 \pm 1.99$ \\
\hline
\end{tabular}

* The difference between the SSD and PI families is nonsignificant for all seven characters.

in all. There are, therefore, 959 degrees of freedom made up of 59 between families, 1 between blocks, 59 for interaction of families and blocks and $60 \times 7 \times 2=840$ for differences between replicate plants within families within blocks. Due to random losses the latter are reduced to 816 for five characters and 815 for the other two (FT and HFT).

For the PI lines we have 784 families divided equally between the two blocks on the basis of their $F_{2}$ origin (see section 2) with 8 replicate plants (full sibs) per family, making 6272 plants in all. The total of 6271 degrees of freedom is made up of $96(48 \times 2)$ between $F_{7}$ groups of 8 families within each block each group having been derived from a different $F_{2}$ plant, 1 between blocks, 98 between the $98 \mathrm{~F}_{7}$ pairs of groups of 4 families, each pair having been derived from a pair of sibs of an $F_{3}$ family (same $F_{2}$ parent) 196 between the 196 pairs of $F_{7}$ groups of 2 families, each pair having been derived from a pair of sibs of an $F_{4}$ family (same $F_{3}$ parent and $F_{2}$ grandparent), 392 between the 392 pairs of $F_{7}$ families each pair having been derived from a pair of sibs of an $F_{5}$ family (same $F_{4}$ parent, $F_{3}$ grandparent and $F_{2}$ great-grandparent) and $784 \times 7=5488$ for differences between the 8 sibs within the $784 \mathrm{~F}_{7}$ families which are reduced to 5347, 5346 and 5332 for various characters due to random losses (see table 3 ).

The mean squares corresponding with the items of interest in the analysis of variance of the 60 inbred families produced by SSD are presented in table 2. For $\mathrm{H}_{4}, \mathrm{H}_{6}$ and HFT the significant Families $\times$ blocks interaction mean square is the appropriate error for testing the Between families item. For the remaining characters this interaction is non-significant and has been combined with the Within families item to give a pooled error. For all seven characters the Between families mean square is highly significant when tested against the appropriate error. The component of variance between family means is a direct estimate of the additive genetic component of variance, $D$, the expectation of which will depend on whether non-allelic interactions or linkage are present (Jinks and Pooni 1976, 1980, 1981b). These estimates of $D$ for the seven characters are listed in table 4.

The relevant mean squares for the hierarchical analysis of variance of the 784 inbred families produced by pedigree inbreeding are presented in table 3. Each of the four between family items (Between $F_{2}, F_{3}$ and $F_{4}$ 

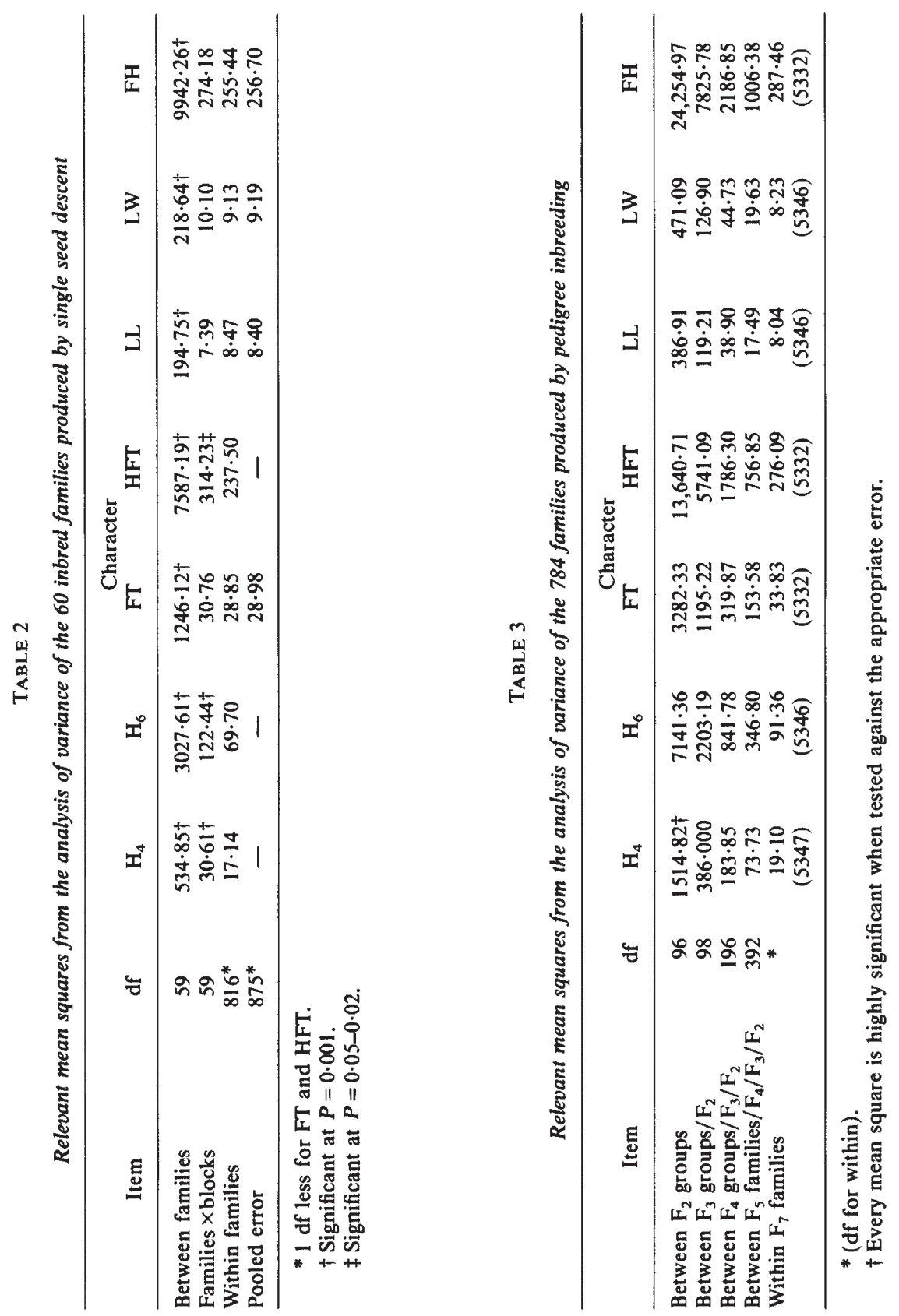
TABLE 4

Estimates of the additive genetic component of variance $D$ for the samples of inbred families produced by single seed descent (SSD) and pedigree inbreeding (PI), respectively

\begin{tabular}{crr}
\hline & \multicolumn{2}{c}{ Source of inbred families } \\
Character & \multicolumn{1}{c}{ SSD } & \multicolumn{1}{c}{ PI } \\
\hline H $_{4}$ & $31 \cdot 32$ & 38.48 \\
H $_{6}$ & $181 \cdot 57$ & $186 \cdot 61$ \\
FT & 76.07 & 87.24 \\
HFT & $454 \cdot 56$ & $380 \cdot 01$ \\
LL & $11 \cdot 65$ & 9.41 \\
LW & 13.09 & $11 \cdot 17$ \\
FH & 605.35 & 609.48 \\
\hline
\end{tabular}

family groups and $F_{5}$ families) is highly significant when tested against the appropriate error for all seven characters. Each of the components of variance between family means is an estimate of a fraction of the additive genetic component of variance, $D$, the expectation of which depends on whether non-allelic interactions or linkage are present (see section 3(ii)). For the present we shall ignore the hierarchical structure of the 784 inbred families and treat them like the SSD inbred families for estimating $\frac{31}{32} D$ as the component of variance $\left(\sigma_{b}^{2}\right)$ between the 784 family means. Fuller analyses which recognise the hierarchical structure will be described in section 3(ii). The estimates of $D$ for all characters are given in table 4 alongside those obtained from the sample of inbred families derived by SSD. There are no significant differences between the paired estimates of $D$ for any character. There are, therefore, no differences ascribable to the source of the inbred families, that is, SSD or PI.

A statistic of particular significance to the plant breeder is the frequency of inbred families derivable from a cross which fall outside of the parental range $\left(>\bar{P}_{1}<\bar{P}_{2}\right)$ or, if the $F_{1}$ shows heterosis, outperform the $F_{1}$. The number of inbred families derived from the cross of varieties 2 and 12 by SSD and PI which meet these specifications are listed in table 5. These are interesting on two counts. First there are no significant differences between

TABLE 5

The number of inbred families produced by single seed descent and pedigree inbreeding that fall outside of the parental range $\left(>\bar{P}_{1}<\bar{P}_{2}\right)$ and the $F_{1}$ range $\left(>\bar{F}_{1}<\bar{F}_{1}\right)$

\begin{tabular}{|c|c|c|c|c|c|c|c|c|}
\hline \multirow[b]{2}{*}{ Character } & \multicolumn{2}{|c|}{$>\bar{P}_{1}$} & \multicolumn{2}{|c|}{$<\overline{\boldsymbol{P}}_{2}$} & \multicolumn{2}{|c|}{$>\bar{F}_{1}$} & \multicolumn{2}{|c|}{$<\bar{F}_{1}$} \\
\hline & SSD* & PI† & SSD* $^{*}$ & $\mathrm{PI} \dagger$ & SSD $^{*}$ & PIt & SSD* & PIt \\
\hline $\mathrm{H}_{4}$ & 12 & 172 & 7 & 109 & 10 & 133 & 50 & 651 \\
\hline $\mathrm{H}_{6}$ & 5 & 60 & 8 & 105 & 1 & 34 & 59 & 750 \\
\hline FT & 18 & 213 & 17 & 245 & 47 & 598 & 13 & 186 \\
\hline HFT & 23 & 333 & 14 & 232 & 27 & 371 & 33 & 413 \\
\hline $\mathbf{L L}$ & 28 & 347 & 30 & 420 & 10 & 91 & 50 & 693 \\
\hline LW & 26 & 311 & 21 & 302 & 8 & 63 & 52 & 721 \\
\hline FH & 22 & 285 & 12 & 157 & 5 & 108 & 55 & 676 \\
\hline
\end{tabular}

* Out of a total of 60 SSD families.

t Out of a total of 784 PI families. 
TABLE 6

$\chi^{2}$ values for the heterogeneity of within family variances of the inbred lines derived by single seed descent and pedigree inbreeding

\begin{tabular}{ccc}
\hline & \multicolumn{2}{c}{$\begin{array}{c}\text { Source of inbred families } \\
\text { SSD }\end{array}$} \\
Character & $\chi^{2}(59)$ & $\begin{array}{c}\text { PI } \\
\chi^{2}(783)\end{array}$ \\
\hline H $_{4}$ & $355.27^{*}$ & 2952.28 \\
H $_{6}$ & 148.71 & 1595.65 \\
FT & 296.29 & 3312.82 \\
HFT & 306.41 & 2972.49 \\
LL & $96.51 \dagger$ & 1490.04 \\
LW & 104.05 & 1310.15 \\
FH & 171.39 & 1991.65 \\
\hline
\end{tabular}

* Everyone of the $\chi^{2}$ values is significant at $p=0.001$ except the one marked + which is significant at $p=0.01$.

the SSD and PI derived samples of inbred families for these statistics. Second these statistics demonstrate once more that there are no difficulties in obtaining inbred families which outperform the highly heterotic $F_{1}$ for any character.

Comparisons of the mean variances of the inbred families produced by SSD and PI (see Within families mean square in tables 2 and 3 ) show that the latter are significantly larger for all except the leaf characters LL and LW. Since the SSD and PI inbred families are $F_{13}$ and $F_{7}$, respectively this result is not surprising as the expected values of these variances on a simple additive-dominance genetic and additive environmental model are $\left(\frac{1}{2}\right)^{n-1} D+\left(\frac{1}{2}\right)^{n} H+E$ for $n=13$ and 7 . While, therefore, these variances are

\section{TABLE 7}

Maximum likelihood estimates of the heritable components of variation obtained by fitting 3 models to the pedigree inbreeding data, model (1) assuming linkage equilibrium and no non-allelic interaction, model (2) assuming no non-allelic interaction and model (3) no linkage disequilibrium

\begin{tabular}{|c|c|c|c|c|c|c|c|c|}
\hline \multirow[b]{2}{*}{ Character } & \multicolumn{2}{|l|}{ Model (1) } & \multicolumn{3}{|c|}{ Model (2)* } & \multirow[b]{2}{*}{$D_{6}$ to $D_{\infty}$} & \multicolumn{2}{|c|}{ Model (3) } \\
\hline & D & $\mathrm{D}_{1}$ & $\mathrm{D}_{2}$ & $D_{3}$ & $\mathrm{D}_{4}+\mathrm{D}_{5}$ & & $\mathrm{D}$ & I \\
\hline $\mathbf{H}_{4}$ & $55 \cdot 36$ & 29 & & & 66.40 & & - & - \\
\hline $\mathbf{H}_{6}$ & $263 \cdot 36$ & 155 & & & 310.75 & & - & - \\
\hline FT & $120 \cdot 55$ & $68 \cdot 11$ & & & & & - & - \\
\hline HFT & $518 \cdot 76$ & $224 \cdot 62$ & & & 574.55 & & - & - \\
\hline LL & $10 \cdot 81$ & - & 一 & - & - & - & - & 一 \\
\hline LW & $12 \cdot 77$ & - & 一 & - & - & - & - & - \\
\hline FH & $758 \cdot 58$ & 579 & & & $841 \cdot 00$ & & 344.96 & $276 \cdot 75$ \\
\hline
\end{tabular}

${ }^{*} D_{r}$ for $r=1$ to $\infty$ is given by the general formula

$$
D_{r}=\sum d_{j}^{2}\left(\begin{array}{c}
+C \\
-R
\end{array}\right) \sum 2\left(1-2 p_{j k}\right)^{r} d_{j} d_{k} \quad \text { (Jinks and Pooni, 1982). }
$$

The bracketed $D$ 's do not differ significantly and have been jointly estimated, the unbracketed $D$ 's differ significantly. 
TABLE 8

The environmental components of variation, $E$ of the inbred families produced by single seed descent and pedigree inbreeding, the latter having been obtained by fitting models to the mean squares given in table 3

\begin{tabular}{|c|c|c|c|c|c|}
\hline \multirow[b]{3}{*}{ Character } & \multicolumn{4}{|c|}{ Source of inbred families } & \multirow{3}{*}{$\begin{array}{l}\chi^{2} \text { heterogeneity } \\
(1 \mathrm{df})\end{array}$} \\
\hline & \multicolumn{2}{|c|}{ SSD } & \multicolumn{2}{|c|}{ PI } & \\
\hline & $\mathrm{E}$ & df & E & df & \\
\hline $\mathrm{H}_{4}$ & $17 \cdot 14$ & 816 & $17 \cdot 04$ & 5347 & $0.01^{\mathrm{NS}}$ \\
\hline $\mathrm{H}_{6}$ & $69 \cdot 70$ & 816 & 81.74 & 5346 & $7 \cdot 42^{* *}$ \\
\hline FT & 28.85 & 815 & 28.91 & 5332 & $0.00^{\mathrm{NS}}$ \\
\hline HFT & $237 \cdot 50$ & 815 & $258 \cdot 61$ & 5332 & $2 \cdot 30^{\mathrm{NS}}$ \\
\hline $\mathrm{LL}$ & $8 \cdot 47$ & 816 & $7 \cdot 73$ & 5346 & $3 \cdot 15^{\mathrm{NS}}$ \\
\hline LW & $9 \cdot 13$ & 816 & 7.86 & 5346 & $8 \cdot 69^{* *}$ \\
\hline FH & 255.44 & 816 & $261 \cdot 64$ & 5332 & $0 \cdot 15^{\mathrm{NS}}$ \\
\hline
\end{tabular}

NS $P>0.05 ;{ }^{* *} P \leqq 0.01$.

essentially estimates of the non-heritable component $E$ there will be a much larger residual heritable component in the PI than in the SSD sample. Further comparison must, therefore, await the separation of the genetical and environmental components of variation (section 3(ii) tables 7 and 8).

Bartlett's tests of the homogeneity of the within family variances show highly significant heterogeneity within both the SSD and PI samples of inbred families for every character (table 6). There can be no doubt that genotype $\times$ environment interaction is responsible for this heterogeneity in the $F_{13}$ SSD sample and this must be a major contributor in the $F_{7}$ PI sample as well.

(ii) Comparison of the genetical information obtainable from SSD and PI
families

The limited structure within the random sample of inbred families produced by SSD allows the variance and higher order statistics to be partitioned into within and between family items only (table 2). With highly inbred families this partitioning readily allows the separation of non-heritable from heritable sources of variation but nothing more than this.

In contrast, the hierarchical structure within the random sample of inbred families produced by PI allows the total variance and higher order statistics and hence the heritable sources of variation to be partitioned (table 3 ). In the present data the variance can be partitioned amongst five mean squares whose expectations for the heritable component can be given in terms of components of variance $\sigma_{r}^{2}$ for $r=1$ to $\infty$. Following Jinks and Pooni (1981 $b$ ) and Mather and Jinks (1982) their expectations can be derived from the appropriate general formula. Since the coefficient of the dominance component is so small (it ranges from $\frac{1}{128}$ down to $\frac{1}{4096}$ ) that it can be considered as zero for all practical purposes, its contribution to the expectations will be omitted. We shall, therefore, include only the additive genetic and additive $\times$ additive genetic interactions in the general formulae. They then become:

Model (1) $\sigma_{r}^{2}=\left(\frac{1}{2}\right)^{r} \sum d_{j}^{2}$, if we assume linkage equilibrium and no non-allelic interaction; 
Model (2)

$$
\sigma_{r}^{2}=\left(\frac{1}{2}\right)^{r}\left[\sum d_{j}^{2}\left(\begin{array}{c}
+C \\
-R
\end{array}\right) \sum 2\left(1-2 p_{j k}\right)^{r} d_{j} d_{k}\right],
$$

if we assume no non-allelic interaction;

Model (3)

$$
\sigma_{r}^{2}=\left(\frac{1}{2}\right)^{r} \sum d_{j}^{2}+\left[\left(\sum_{i=1}^{r} 2^{r}-1\right) / 4^{r}\right] \sum i_{j k}^{2},
$$

if we assume linkage equilibrium; and

Model (4)

$$
\begin{aligned}
\sigma_{r}^{2}= & \left(\frac{1}{2}\right)^{r}\left[\sum d_{j}^{2}\left(\begin{array}{c}
+C \\
-R
\end{array}\right) \sum 2\left(1-2 p_{j k}\right)^{r} d_{j} d_{k}\right] \\
& +\left[\left\{\left(\frac{1}{2}\right)^{r-2} \sum_{j j=0}^{r-2}\left(1-2 p_{j k}-2 p_{j k}^{2}\right)^{j j}\right\} p_{j k}\left(1-p_{j k}\right)\right. \\
& \left.+\left\{\frac{1}{2}\left(1-2 p_{j k}+2 p_{j k}^{2}\right)\right\}^{r-1} \frac{2 p_{j k}+2 p_{j k}^{2}\left(1-2 p_{j k}\right)^{2}}{\left(1-2 p_{j k}\right)^{2}}\right] \sum i_{j k}^{2}
\end{aligned}
$$

if we make no assumptions.

In these generalised expectations $r=1$ to $\infty$ is the rank of the statistic in the hierarchical analysis; thus in table 3

$r=1$ corresponds with Between $F_{2}$ groups of $F_{7}$ families;

$r=2$ corresponds with Between $F_{3}$ groups of $F_{7}$ families within $F_{2}$ groups;

$r=3$ corresponds with Between $\mathrm{F}_{4}$ groups of $\mathrm{F}_{7}$ families within $\mathrm{F}_{3}$ and $\mathrm{F}_{2}$ groups;

$r=4$ and $r=5$ correspond with Between $F_{5}$ grandparents of $F_{7}$ families within $F_{4}, F_{3}$ and $F_{2}$ groups which, because only one $F_{6}$ parent was taken from each $F_{5}$ grandparent to produce the $F_{7}$ families, also contains the Between $F_{6}$ parent of $F_{7}$ families component of variation; and

$r=6$ to $\infty$ corresponds with Within $F_{7}$ families which contains all of the residual heritable variation (section $3(\mathrm{i})$ ).

Estimates of the significant heritable components obtained by fitting the models using maximum likelihood procedures (Mather and Jinks, 1982) to the mean squares of the hierarchical analysis of variance of the PI inbred family data (table 3 ) are given in table 7 . Following standard procedure, estimates of the components in the more complex models are presented only where they give a better fit to the data than the simpler models. Estimates of the environmental components of variance are presented separately in table 8 so that they can be compared with the corresponding estimates from the SSD families.

Model (1), which assumes linkage equilibrium and no non-allelic interaction, is satisfactory for LL and LW only. For $\mathrm{H}_{4}, \mathrm{H}_{6}$ and $\mathrm{FH}$ it is unsatisfactory because there is sufficient linkage disequilibrium to make $D_{1}=D_{2}$, the rank 1 and $2(r=1$ and 2) forms of $D$ in model (2) significantly smaller than $D_{3}$ to $D_{\infty}$, the rank 3 to $\infty$ forms of $D$. For HFT it is unsatisfactory 
because a linkage disequilibrium is making $D_{1}$ significantly smaller than $D_{2}$ to $D_{\infty}$ while for FT it is making $D_{1}$ significantly smaller than $D_{2}=D_{3}$ which are significantly smaller than $D_{4}$ to $D_{\infty}$. For the five characters where model (1) is not satisfactory, model (2), which allows for a linkage disequilibrium, is, therefore, satisfactory. In contrast model (3), which allows for non-allelic interaction, is a satisfactory alternative for $\mathrm{FH}$ only. For no character is it necessary to consider allowing for linkage disequilibrium and non-allelic interaction simultaneously (model (4)).

Reference to table 8 shows that the estimates of the environmental components of variation obtained from the maximum likelihood model fitting to the PI data agree remarkably well with the direct estimates from the mean within family variances of the inbreds produced by SSD. However, because of the large numbers of degrees of freedom the $E$ 's for $\mathrm{H}_{6}$ and LW differ significantly between the PI and SSD samples of inbred families.

\section{Conclusions}

The main conclusion from the analyses in section $3(i)$ is that the phenotypic and genotypic properties of the random samples of inbred families are the same whether they are extracted from the cross by single seed descent or by pedigree inbreeding, the only difference being explained by their different levels of inbreeding $\left(F_{13}\right.$ and $\left.F_{7}\right)$. This empirically based conclusion agrees with biometrical genetical expectations which make no assumptions about gene action and interaction, linkage and genotype $x$ environment interactions. The choice between the two methods of extraction can, therefore, be made without reference to genetical considerations. If, however, selection based upon field trials, which are part of the normal pedigree inbreeding but not of the single seed descent inbreeding programmes, significantly increases the frequency of rare, useful genotypes above their random frequencies (table 5) then there may be advantages in pedigree inbreeding not revealed by our analyses. While previous studies with $N$. rustica suggest that early generation selection is not useful (Jinks and Pooni 1981 $a$ ) the effect of such selection on our PI families will be the subject of a further paper.

The main conclusion from the analyses in section 3(ii) is that the random sample of inbred families produced by PI allows a more sophisticated biometrical genetical analysis than that produced by SSD. Both allow the separation of heritable and non-heritable sources of variation and in the highly inbred material the former arises almost entirely from the additive action of the genes. In addition, however, the sample produced by PI, because of its hierarchical structure, allows the presence of a linkage disequilibrium and of non-allelic interaction to be detected, the magnitude of their effects measured, and the phase of the disequilibrium determined. Thus in the $N$. rustica data it has allowed us to obtain unambiguous evidence of repulsion linkages for most characters but not of the non-allelic interactions which other investigations of the same cross have detected (Pooni, Jinks and Jayasekara, 1978; Pooni and Jinks, 1981b, 1982, 1983a, 1983b). In spite of an exceptionally large number of families (784) and the complex hierarchical structure, the analysis of the inbreds produced by PI is not, therefore, particularly sensitive for the detection and estimation of the non-allelic interaction components of variation. 


\section{REFERENCES}

JINKS, J. L. 1983. Biometrical genetics of heterosis. In Frankel, R. (ed.) Heterosis, SpringerVerlag, Berlin, pp. 1-46.

JINKS, J. L. AND POONI, H. S. 1976. Predicting the properties of recombinant inbred lines derived by single seed descent. Heredity, 36, 253-266.

JINKS, J. L. AND POONI, H. S. 1980 . Comparing prediction of mean performance and environmental sensitivity of recombinant inbred lines based upon $F_{3}$ and triple test cross families. Heredity, 45, 305-312.

JINKS, J. L. AND POONI, H. S. 1981a. Comparative results of selection in the early and late stages of an inbreeding programme. Heredity, 46, 1-7.

JINKS, J. L. AND POONI, H. S. 1981 b. Properties of pure breeding lines produced by dihaploidy, single seed descent and pedigree breeding. Heredity, 46, 391-395.

JINKS, J. L. AND POONI, H. S. 1982. Predicting the properties of pure breeding lines extractable from a cross in the presence of linkage. Heredity, 49, 265-270.

KEARSEY, M. J. AND JINKS, J. L. 1968. A general method of detecting additive, dominance and epistatic variation for metrical traits. I. Theory. Heredity, 23, 403-409.

MATHER, K. AND Jinks, J. L. 1982. Biometrical Genetics. 3rd edn. Chapman and Hall, London.

POONI, H. S. AND JINKS, J. L. 1978. Predicting the properties of recombinant inbred lines derived by single seed descent for two or more characters simultaneously. Heredity, 40, 349-361.

POONI, H. S. AND JINKS, J. L. 1979. Sources and biases of the predictors of recombinant inbreds derived by single seed descent. Heredity, 42, 41-48.

POONI, H. S. AND JINKS, J. L. $1981 a$. Sources of predictions and their reliability in predicting the properties of recombinant inbred lines which can be obtained from a cross by single seed descent. Proceedings of the Fourth International Barley Genetics Symposium, Edinburgh, Scotland, pp. 73-78.

POONI, H. S. AND JINKS, J. L. $1981 \mathrm{~b}$. The true nature of the non-allelic interactions in Nicotiana rustica revealed by association crosses. Heredity, 47, 253-258.

POONI, H. S. AND IINKS, J. L. 1982. Comparative analysis of association and dispersion crosses to detect linkage and epistatic components of variation. Heredity, 49, 211-220.

POONI, H. S. AND JINKS, J. L. 1983a. Comparison of associated and dispersed testers in the triple test cross. Heredity. 50, 73-83.

POONI, H. S. AND JINKS, J. L. $1983 \mathrm{~b}$. Joint analysis of triple test crosses of a single population with associated and dispersed inbred testers. Heredity, 50, 311-320.

POONI, H. S., JINKS, J. L. AND JAYASEKARA, N. E. M. 1978. An investigation of gene action and genotype $\times$ environment interaction in two crosses of Nicotiana rustica by triple test cross and inbred line analysis. Heredity, 41, 83-92.

POONI, H. S., JINKS, J. L. AND POONI, G. S. 1978. A general method for detection and estimation of additive, dominance and epistatic variation for metrical traits. IV. Triple test cross analysis for normal families and their selfs. Heredity, 44, 177-192. 